\title{
FOLLOWUP PATTERN OF PSYCHIATRY PATIENTS IN TERTIARY CARE CENTRE OF CENTRAL INDIA
}

\author{
Manoj Kumar Sahu1, Lokesh Kumar Singh², Sharda Singh ${ }^{3}$
}

${ }_{1}^{1}$ Associate Professor, Department of Psychiatry, Pt. JNM Medical College, Raipur, Chhattisgarh.

${ }^{2}$ Associate Professor, Department of Psychiatry, All India Institute of Medical Sciences, Raipur, Chhattisgarh. ${ }^{3}$ Clinical Psychologist, Department of Psychiatry, Pt. JNM Medical College, Raipur, Chhattisgarh.

\section{ABSTRACT}

\section{BACKGROUND}

Psychiatric illnesses usually require long-term treatment for better outcome. It has been common observation that person with mental illness tends to stop medication against advice of treating psychiatrist.

The present study was aimed to compare the demographic and clinical profiles of psychiatric patients attending outpatient department who remain in followup with those who do not.

\section{MATERIALS AND METHODS}

This study was a retrospective data analysis conducted at Outpatient Department of Psychiatry, Pt. Jawaharlal Nehru Memorial Medical College and Dr. B. R. Ambedkar Memorial Hospital, Raipur, Chhattisgarh, India. All cases attending the OPD from January 2014 to June 2015 were included in this study. Socio-demographic data, diagnosis and followup information were obtained from the patients, guardians and prescriptions slip. The collected data were analysed using descriptive analysis and Chi-square test.

\section{RESULTS}

28.4\% of the patients dropped out after first visit, $61.5 \%$ patients had $1-3$ followup, $8.3 \%$ had $4-7$ followups and only $1.7 \%$ had more than 8 followups. Statistically significant correlation was found between followup and various socio-demographic variables such as educational level, distance from hospital and family history of psychiatric illness.

\section{CONCLUSION}

In our study, $28.4 \%$ of the patients did not attend followup at all and only $1.7 \%$ had more than 8 followups. Patient's retention into treatment loop is quite encouraging, still more strategies can be tried to enhance the followup rate.

\section{KEYWORDS}

Compliance, Followup, Psychiatric Illness.

HOW TO CITE THIS ARTICLE: Sahu MK, Singh LK, Singh S. Followup pattern of psychiatry patients in tertiary care centre of Central India. J. Evolution Med. Dent. Sci. 2017;6(37):2987-2989, DOI: 10.14260/Jemds/2017/644

\section{BACKGROUND}

Psychiatric illnesses present with inter-individual variability across different diagnostic entity. Better outcome of these condition is determined by adherence to the treatment. It has been common observation that person with mental illness tends to stop medication against advice of treating psychiatrist. The issues of followup rate, profile of patients with psychiatric illness, factors affecting continuation in treatment were studied for many decades and continue to be of interest in present.1,2,3 These kinds of studies are important for mental health professionals as well as policy makers.

Moreover, it appears that none of these factors are constant as changes in medical facilities in terms of availability of beds and newer methods of treatment and medicines, availability of super specialties, increasing awareness and acceptance regarding psychiatric illness,

Financial or Other, Competing Interest: None.

Submission 01-04-2017, Peer Review 24-04-2017,

Acceptance 01-05-2017, Published 08-05-2017.

Corresponding Author:

Dr. Manoj Kumar Sahu,

Department of Psychiatry,

Pt. JNM Medical College,

Raipur-492001,

Chhattisgarh, India.

E-mail:drmanojksahu@gmail.com

DOI: $10.14260 /$ jemds $/ 2017 / 644$ economic affordability and like factors bring related change not only in patient profile but also in kind of requirement in psychiatric treatment. Study gives good insight into these factors. ${ }^{1}$

Research also indicates that in psychiatry, dropout patients are of more worrisome as reason for not coming back for treatment is anything but wellness. Previous studies have shed lights that those who drop from treatment have more adverse characteristics compared to those who remain in followup. Patients with poor drug compliance are having more chances to be admitted in future due to flaring up of the symptoms. ${ }^{4}$ The present study aimed to compare the demographic and clinical profiles of psychiatric patients attending outpatient department who remain in followup with those who do not.

\section{MATERIALS AND METHODS}

This study was a retrospective data analysis conducted at Outpatient Department of Psychiatry, Pt. Jawaharlal Nehru Memorial Medical College and Dr. B. R. Ambedkar Memorial Hospital, Raipur, Chhattisgarh, India. The study protocol was approved by Institutional Ethics Committee, Pt. JNM Medical College, Raipur. All cases attending the Outpatient Department from January 2014 to June 2015 were included in this study. Socio-demographic data, diagnosis and followup information were obtained from the patients and guardian. The collected data were analysed using Descriptive analysis and correlation. 


\section{RESULTS}

Total 7876 patients were registered in the study with the mean age of 34.4 years. The number of males (64.3\%) was higher as compared to the females. More number of patients $(68.3 \%)$ was married. Majority of the patients (67.6\%) were coming within 10 kilometres distance from hospital. Majority of patients (91.7\%) belonged to Hindu religion and $44.1 \%$ were working during the study period. Primary level of education was attended by $85.5 \%$. Only $13.7 \%$ of study participants had family history of psychiatric illness. Good number of patients $(60.1 \%)$ reported to be compliant to the medication (Table 1).

About $28.4 \%$ of the patients dropped out after the first visit, $61.5 \%$ had $1-3$ followups, $8.3 \%$ had $4-7$ followups. Only $1.7 \%$ had more than 8 followups (Graph 1). The most common psychiatric disorders were schizophrenia $(23.3 \%)$ followed by depression (15.3\%), bipolar disorder $(8.4 \%)$, substance abuse disorder (6.4\%), anxiety disorder $(6.2 \%)$ and mental retardation (6.2\%) (Table 2).

Statistically significant correlation was found between followup and various socio-demographic variables such as educational level distance from hospital and family history of psychiatric illness. Patient's level of education and presence of family history were found to have statistically significant positive correlation with followup, whereas distance from hospital to patient's place of residence was found to have statistically significant negative correlation with followup (Table 3).

\begin{tabular}{|c|c|c|}
\hline Demographic Parameters & \multicolumn{2}{|c|}{ Statistics } \\
\hline Age & Mean (SD) & 33.62 (14.61) \\
\hline Gender & Frequency & Percent \\
\hline Male & 5068 & 64.3 \\
\hline Female & 2808 & 35.7 \\
\hline Marital Status & Frequency & Percent \\
\hline Never Married & 2414 & 30.7 \\
\hline Married & 5392 & 68.5 \\
\hline Separated/Divorced/Widowed & 64 & 0.8 \\
\hline Other & 6 & 0.1 \\
\hline Education & Frequency & Percent \\
\hline Illiterate & 128 & 1.6 \\
\hline
\end{tabular}

\begin{tabular}{|c|c|c|}
\hline Primary & 6736 & 85.5 \\
\hline School & 268 & 3.4 \\
\hline Graduation & 690 & 8.8 \\
\hline Post-Graduation & 54 & 0.7 \\
\hline Distance & Frequency & Percent \\
\hline$<10 \mathrm{~km}$ & 5326 & 67.6 \\
\hline $11-50 \mathrm{~km}$ & 784 & 10.0 \\
\hline $51-100 \mathrm{~km}$ & 978 & 12.4 \\
\hline $101-200 \mathrm{~km}$ & 438 & 5.6 \\
\hline$>200 \mathrm{~km}$ & 350 & 4.4 \\
\hline Religion & Frequency & Percent \\
\hline Hindu & 7220 & 91.7 \\
\hline Muslim & 636 & 8.1 \\
\hline Other & 20 & 0.3 \\
\hline $\begin{array}{l}\text { Family History of } \\
\text { Psychiatric Illness }\end{array}$ & Frequency & Percent \\
\hline Present & 1078 & 13.7 \\
\hline Absent & 6798 & 86.3 \\
\hline
\end{tabular}

\begin{tabular}{|c|c|c|}
\hline & Diagnosis & Total Patients (\%) \\
\hline 1 & Schizophrenia & $1836(23.3)$ \\
\hline 2 & Acute Psychosis & $490(6.2)$ \\
\hline 3 & Other Psychosis & $232(2.9)$ \\
\hline 4 & Bipolar disorder & $658(8.4)$ \\
\hline 5 & Depression & $1204(15.3)$ \\
\hline 6 & OCD & $172(2.2)$ \\
\hline 7 & Anxiety Disorder & $492(6.2)$ \\
\hline 8 & Alcohol and other substance & $502(6.4)$ \\
\hline 9 & Disorder & $490(6.2)$ \\
\hline 10 & Dental Retardation & $140(1.8)$ \\
\hline 11 & Dementia & $20(0.3)$ \\
\hline 12 & Seizure Disorder & $178(2.3)$ \\
\hline 13 & Others & $1426(18.1)$ \\
\hline 14 & Not Diagnosis & $16(0.2)$ \\
\hline Total & 7876 & \\
\hline \multicolumn{2}{|c|}{ Table 2. Patients with Psychiatric Diagnosis } \\
\hline \multicolumn{2}{|c|}{}
\end{tabular}

\begin{tabular}{|c|c|c|c|c|c|c|c|c|}
\hline & & Gender & Age & Distance & Occupation & Marital Status & Education & Family History \\
\hline \multirow{2}{*}{ Followup } & Kendall's tau-b & 0.016 & 0.003 & $-0.046^{* *}$ & 0.010 & 0.016 & $-0.080^{* *}$ & $0.030^{* *}$ \\
\cline { 2 - 9 } & Sig. (2-tailed) & 0.168 & 0.773 & 0.000 & 0.336 & 0.143 & 0.000 & 0.008 \\
\hline \multicolumn{8}{|c|}{ Table 3. Correlation is significant at the 0.01 level (2-tailed) } \\
\hline
\end{tabular}

\section{DISCUSSION}

Patients with psychiatric illness are required to be on regular treatment for favourable outcome. In our study, $28.4 \%$ of the patients dropped out after the first visit. It is also reported that in one study $20 \%-57 \%$ of their patients failed to return after the first visit and 31\% - 56\% attended no more than 4 times. ${ }^{3}$ Other studies from India have reported more dropout as compared to our study. Recent studies reported that $50 \%$ to $53.1 \%$ patients never came for followup.5,6 Patients attending our OPD are also getting free medication and there was no consultation fee for those visits. These facility for the patients and their caregiver may act as a motivating factor resulting in low dropout rates. Availability of other medical services under one roof in government run multispecialty hospital can also be another factor for catering more number of patients in comparison to costlier medical facilities of private sector. A study reporting higher dropout rate was conducted in a private sector psychiatric facility. ${ }^{6}$

We also found that only $1.7 \%$ had more than 8 followups, which is less than reported by another recent study. ${ }^{6}$ They found that $2.6 \%$ had more than 10 followups. Here, it is important to note that we are mentioning the number of followups, whereas time span might be a better measure. It is so because the present and one recent study has reviewed data of one year only. ${ }^{5}$ We found higher dropout rate in long term. 
Similarly, one study reported that chance of rehospitalisation is greater, that is one in four among the nonfollowup patients compared to one in ten among those who remain in followup. ${ }^{7}$

While looking for correlation between followup and various socio-demographic data, distance from hospital to patient's place of residence was found to have statistically significant negative correlation with followup ( $\left.p-0.00^{* *}\right)$. This finding substantiated the fact that service utilisation will be more with easy accessibility; hence, patients living in close vicinity to hospital had more number of followups. Presence of family history was associated with better treatment adherence. This finding can be explained by the effect of priming in the family and they were remaining in followup whenever another family member had any such illness. Patients with higher educational level were remaining more in followup, as it was expected to have positive impact in service utilisation.

Apart from these observations, there may be other factors related to treatment continuation which may be governed by combination of patient and clinician variables. Moreover, not only illness and demographic variables of patient but also psychological namely personality, motivation, relation with family members and so on should be studied to find profile of patients who remain in treatment. Future studies should take account of this complex interaction among different variables.

\section{CONCLUSION}

Recently, there is wide spread awareness and acceptance about mental health. In our study, $28.4 \%$ of the patients did not attend followup at all and only $1.7 \%$ had more than 8 followups. Patient's retention into treatment loop is quite encouraging, still more strategies can be tried to enhance the followup rate.

\section{REFERENCES}

[1] Kala AK, Kala R, Bathia JC. Changing sociodemographic and clinical profile of patients attending a general hospital psychiatric clinic: some indications of community acceptance. Indian J Psychiat 1981;23(1):86-9.

[2] Kaur J, Chavan BS, Sharma A, et al. Study of factors associated with drop out after first visit to psychiatric clinic. JMHHB 2009;14(2):87-94.

[3] Dodd J. A retrospective analysis of variables related to duration of treatment in a university psychiatric clinic. J Nerv Ment Dis 1970;151(2):75-84.

[4] Killaspy H, Banerjee S, King $M$, et al. Prospective controlled study of psychiatric out-patients nonattendance. Characteristics and outcome. $\mathrm{Br} \mathrm{J}$ Psychiatry 2000;176:160-5.

[5] Singla M, Goyal SK, Sood A, et al. Profile and pattern of follow-ups of psychiatry outpatients at christian medical college, Ludhiana. J Mental Health Hum Behav 2015;20(2):76-9.

[6] Agarwal AK. Analysis of patients attending a private psychiatric clinic. Indian J Psychiatry 2012;54(4): 356-8.

[7] Nelson EA, Maruish ME, Axler JL. Effects of discharge planning and compliance with outpatient appointments on readmission rates. Psychiatr Serv 2000;51(7):885-9. 